\title{
Association between Performance and Injury with Dietary Intake and Nutritional Status among Athletes: Case of Iten Training Camp in the Rift Valley of Kenya
}

\author{
*Caroline Tanui, Jasper K. Imungi, Sophie Ngala. \\ Department of Food Science, Nutrition and Technology, Faculty of Agriculture, University of Nairobi P.O BOX \\ 29053 - 00625 Kangemi, Nairobi, KENYA \\ Corresponding Author: Caroline Tanui
}

\begin{abstract}
The objective of this study was to assess the relationship of dietary intake of energy, iron, calcium and nutritional status of athletes with injuries and performance during training. A cross sectional study design was carried out on 282 athletes (192 males and 90 females) between 18 - 30 years participating in middle and long distance races. Socio demographic, socio-economic characteristics, injuries and performance were assessed using a pretested semi structured questionnaire. Dietary intake of energy, calcium and iron was determined using an individual 24- hour dietary recall method and nutrient intakes computed using Nutrisurvey and food composition table. Nutritional status of athletes was measured as BMI. Results showed that major hindrances to expected performance were injury, loss of breath and fatigue. More females were at risk of suffering injuries than males. Dietary intake of energy, calcium and iron were low especially among females. Only 6.3\% of females met the RDA for energy, $12.3 \%$ met the RDA for calcium and none of them met the RDA for iron. The nutritional status of athletes in terms of BMI was poor with significantly more females being underweight compared to male athletes. The study concluded that adequate dietary intake of energy, calcium and iron, and nutritional status of athletes are necessary to ensure performance and obviate injury.
\end{abstract}

Keywords: BMI, Dietary Intake, Injuries, Nutritional status, RDA

\section{Introduction}

Kenyan athletes are renowned over the World for their endurance running in middle and long distance races. They have won approximately $40 \%$ of the major international races in this category that they have participated in during the last decade Fudge, $(2006){ }^{[1]}$. However, the athletes have on occasion suffered injuries during/ prior to competition and these have impacted their performance. These injuries are presumed to be nutrition related, and inadequate dietary intake of energy and micronutrients especially iron and calcium. Over the years nutrition has been identified as the key component to athletes training regimen. It is believed that aside from the limits imposed by heredity and training, no single factor plays a greater role in optimizing performance than diet Tipton, (2010) ${ }^{[2]}$. The International Association of Athletic Federations (IAAF) ${ }^{[3]}$ Consensus Statement on Nutrition for athletics (2007) states that well chosen foods will help athletes train hard, reduce risk of illness and injury, and achieve performance goals, regardless of the diversity of events, environments, nationality and level of competitors.

Training for sports in Kenya is not organized by the Government and is left to individual or group initiative. Little of is therefore known about dietary practices, nutritional status and training habits of Kenyan athletes, and indication are that there is no structured nutrition training program for the athletes. The dietary intake of many athletes follows population diet rather than public health or sports nutrition recommendations. The diets of Kenyan athletes consist mainly of their basic staple diets based predominantly on energy rich foods including cereals and root crops. These have been presumed to provide adequate nutrition for efficient and effective performance if adequately consumed. Female athletes are more vulnerable to poor nutrition resulting to poor performance and injuries because they strive to achieve a lower body weight or low body fat content which may increase the risk of amenorrhea, negative energy balance and eating disorders consequently affecting performance negatively. A good diet helps support consistent intensive training while reducing the risk of illness or injury, improving recovery time and maximizing exercise performance Burke et al., (2001) ${ }^{[4]}$. Therefore, adopting the required practice of sports nutrition would help develop sound eating habits for optimal athletic performance and provide lifetime health benefits for the athletes. Therefore this study was designed to evaluate the association of performance and injury with dietary intake and nutritional status engaged in regular practice in a training camp. 


\subsection{Study Design}

\section{Study Design And Methodology}

A cross sectional study design was used where 282 athletes were selected randomly and proportionate to size sampling allocated to two groups of males (192) and females (90). Each group was divided into middle and long distance runners with the option that one individual could belong to the two categories. The study population comprises of athletes training in Iten training camp including both elite and amateur, middle distance athletes (3000meters, 5000meters, and 10000meters) and long distance (21kilometers and 42kilometers).The sample size calculation was based on the formula by Fischer's et al., (1991) ${ }^{[5]}$ with modification for a population less than 10,000 at $95 \%$ confidence interval.

\subsection{Study Setting}

The study was conducted in Iten training camp, situated in Elgeyo Marakwet County. This is shown in Figure 1. Elgeyo Marakwet County is located in the former Rift valley province. Iten training camp is situated within Iten Township. The camp accommodates around 1500 runners. Iten is at altitude of $2400 \mathrm{~m}$ above the sea level. Elgeyo Marakwet County has a population of 369,998 with a population density of 122 per km ${ }^{2}$ and the tribes residing in the county are Keiyos and Marakwets KNBS, (2009) ${ }^{[6]}$.

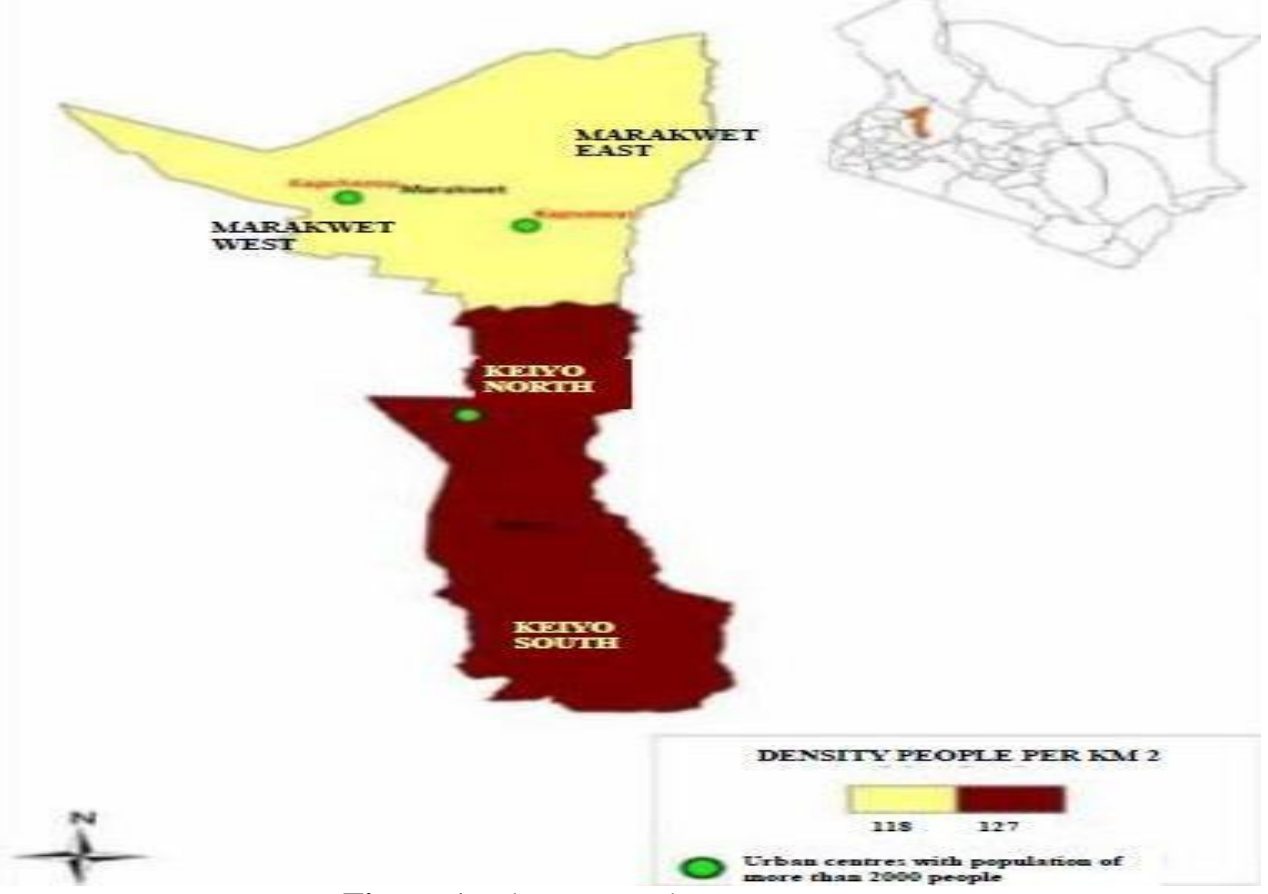

Figure 1: Elgeyo Marakwet county Map

\section{Data Collection}

A pre-tested semi structured questionnaire was used to collect data from the athletes. The questionnaire was structured to contain 24 -hour recall, individual 24 hour dietary diversity score and anthropometry. A 24 hour recall questionnaire was administered to determine dietary intake of energy, calcium and iron. Measurement of food weights and/or the volume equivalent of foods were performed using kitchen diet scale and model utensils including cups, spoons, plates, measuring jars and cooking pans. The national food composition Tables Sehmi, (1993) ${ }^{[7]}$ for Kenya, and the Nutri - survey software were used to compute the energy, calcium and iron consumed by individual athlete within the last 24 hours. Bathroom scales (seca) were used for taking weights and stadiometers (seca) were used to take heights which were used to calculate BMI as a measure of nutritional status. The weighing scales were calibrated regularly to ensure accuracy in taking readings. Performance of athletes was evaluated by comparing world record for the event with the best performance achieved and the differences were graded in terms of time taken for each race. Individual Dietary Diversity scores were determining the numbers of food groups consumed from among the athletes (FAO list of recommended food groups). Data was collected through the assistance of research enumerators who had been trained on the use the study tools. Pre testing of questionnaire was done in Chepkorio training camp in the same county but away from the study camp. This study was approved by the Kenyatta National Hospital/University of Nairobi Ethics and Research Committee and a research permit was obtained from the National Council Science Technology and Innovation (NACOSTI) in the Ministry of Higher Education, Science and Technology. Informed consent was obtained from individual athletes before the commencement of the study. 


\subsection{Data handling and Statistical analysis}

Dietary intake of energy, calcium and iron were computed using Nutri- survey (2007) software and a Kenyan food composition Table Sehmi, (1993) ${ }^{[7]}$. Data was entered into a database using statistical package for social science SPSS (20.0). Data cleaning was done by running frequencies and using explores to check normalities, any missing data, outliers as well as consistency of responses between questions. Socio demographic and socio-economic data were analysed using descriptive statistics and simple frequencies, means and percentages. Chi-square test was used to determine association between variables and the statistical significance concept. Logistic regression analysis was used to calculate odds ratios and linear regression was used to determine the association between variables. The level of significance was set at $\mathrm{P}<0.05$.

\subsection{Socio Demographic Characteristics}

\section{Results}

A total of 282 athletes were assessed in the study with 192 males and 90 females. Most of male athletes were between ages $25-30$ years while most of female athletes were between ages $18-24$ years. Over $60 \%$ of both males and females were single. Majority $(97.8 \%)$ of athletes attained at least primary education. With regards to ethnicity, majority of athletes were from the Kalenjin ethnicity. The results are shown in Table 1.

Table 1: Socio Demographic Characteristics of Athletes

\begin{tabular}{lllll}
\hline Socio Demographic characteristics & Male $(\mathbf{n}=\mathbf{1 9 2})$ & \multicolumn{2}{c}{ Female $(\mathbf{n}=\mathbf{9 0})$} \\
\hline & Frequency & Percentage & Frequency & Percentage \\
\hline Age of athletes (years) & & & & \\
$18-24$ & 90 & 46.9 & 56 & 61.2 \\
$25-30$ & 102 & 53.1 & 34 & 37.8 \\
Marital status & 121 & 63.1 & 55 & 62.1 \\
Single & 71 & 36.9 & 35 & 38.9 \\
Married & & & & \\
Education level & 1 & 0.5 & 2 & 2.2 \\
Never attended school & 66 & 34.4 & 29 & 32.2 \\
Primary level & 116 & 60.4 & 50 & 55.6 \\
Secondary level & 9 & 4.7 & 9 & 10.0 \\
Tertiary level & & & & \\
Ethnicity & 160 & 83.3 & 73 & 81.1 \\
Kalenjin & 4 & 2.1 & 7 & 7.8 \\
Kikuyu & 11 & 5.7 & 0 & 0.0 \\
Turkana & 7 & 3.7 & 1 & 1.1 \\
Masai & 6 & 3.1 & 2 & 2.2 \\
Samburu & 3 & 1.6 & 4 & 4.4 \\
Kisii & 1 & 0.5 & 3 & 3.4 \\
Kamba & & &
\end{tabular}

\subsection{Socio Economic Characteristics of Athletes}

The athletes were placed into the three socio-economic categories of the country as follows: higher class (70,000 KShs per month), middle class (20,000 to 70,000 KShs per month) and lower class (below $20,000 \mathrm{KShs}$ per month). There were slightly more females in the lower class than males, slightly more males in middle class than females and slightly more males in the higher class than females. These results are shown in Table 2. It was indicated that apart from athletics, majority of the athletes obtained their income from either from farming or successful business. A small number were employees of the armed forces of Kenya.

Table 2: Socio Economic Characteristics of Athletes

\begin{tabular}{lllll}
\hline Socio Economic characteristics & Male $(\mathbf{n}=\mathbf{1 9 2})$ & & Female $(\mathbf{n}=\mathbf{9 0})$ \\
\hline Socio Economic class & Frequency & Percentage & Frequency & Percentage \\
\hline Lower class & 75 & 39.1 & 41 & 45.6 \\
Middle class & 94 & 48.9 & 40 & 44.4 \\
Higher class & 23 & 11.9 & 9 & 10 \\
\hline
\end{tabular}

$* 1$ KShs $=\$$ US 0.01

\subsection{Distribution of athletes by Type of Sex of Race}

The races were grouped into two races; middle distance $(3000 \mathrm{~m}, 5000 \mathrm{~m}$ and $10,000 \mathrm{~m})$ and long distance $21 \mathrm{~km}$ and $42 \mathrm{~km}$ (also known as half marathon and full marathon respectively). In all the five races, by far men were the majority except in $5000 \mathrm{~m}$ race. This was even more pronounced in the marathon races. These results are shown in Table 3. 
Table 3: Distribution of the Athletes by Type of Race

\begin{tabular}{lllll}
\hline Type of race & Males $(\mathbf{n}=\mathbf{1 9 2})$ & & Females $(\mathbf{n}=\mathbf{9 0})$ & Percentage \\
\hline Middle distance & Frequency & Percentage & Frequency & 10.0 \\
\hline $3000 \mathrm{~m}$ & 13 & 6.8 & 9 & 15.6 \\
$5000 \mathrm{~m}$ & 9 & 4.7 & 14 & 22.2 \\
$10,000 \mathrm{~m}$ & 46 & 23.9 & 20 & 30.0 \\
Long distance & & & & 22.2 \\
$21 \mathrm{Km}$ & 61 & 31.7 & 27 & 20 \\
$42 \mathrm{Km}$ & 63 & 32.8 & & \\
\hline
\end{tabular}

\subsection{Performance of athletes}

The performance was categorized into excellent, good, fair and poor. This was established through ranking against the world record for the event, the best performance achieved by individual athlete. Excellent performance was measured as difference between the best world record and the best record achieved by individual athlete record achieved is less or equal to one minute, Good performance; greater than one minute and less than three minutes, Fair performance; greater than three minutes and less or equal to five minutes and Poor performance; greater than five minutes. Of the male athletes $17.7 \%$ had excellent performance, slightly lower than the female athletes with $21.1 \%$. More females had poor performance as compared to male athletes as shown in Table 4.

Table 4: Distribution of Athletes by Performance

\begin{tabular}{lllll}
\hline Performance levels of athletes & \multicolumn{2}{c}{ Male $(\mathbf{n}=\mathbf{1 9 2})$} & \multicolumn{2}{c}{ Female $(\mathbf{n}=90)$} \\
\hline & Frequency & Percentage & Frequency & Percentage \\
\hline Excellent & 34 & 17.7 & 19 & 21.1 \\
Good & 107 & 55.7 & 44 & 48.9 \\
Fair & 32 & 16.7 & 13 & 14.4 \\
Poor & 19 & 9.9 & 14 & 15.6 \\
\hline
\end{tabular}

\subsubsection{Hindrance to Expected Performance}

According to the athletes, major hindrances to expected performance were injury, running out of breath and fatigue. More male athletes experienced injury as a major hindrance to their expected performance compared to the female athletes. The hindrance to expected performance of most of the female athletes was running out of breath and fatigue as compared to male athletes. These results are shown in Table 5.

Table 5: Hindrance to expected Performance

\begin{tabular}{lllll}
\hline Hindrance to expected performance & \multicolumn{2}{c}{ Male $(\mathbf{n}=\mathbf{1 9 2})$} & \multicolumn{2}{c}{ Female $(\mathbf{n}=90)$} \\
\hline & Frequency & Percentage & Frequency & Percentage \\
Injury & 147 & 76.6 & 32 & 35.6 \\
Running out of breath & 19 & 9.9 & 29 & 32.2 \\
Fatigue & 26 & 13.5 & 29 & 32.2 \\
\hline
\end{tabular}

\subsection{Common Injuries suffered by Athletes}

Injuries that were common to athletes included hamstring, tendon, muscle cramps and ankle injuries yet majority of the athletes assumed that it was normal to suffer from this common injuries. There was a very small difference between female and male who suffered from common injuries that affected their performance. More males suffered from hamstring while more females suffered from muscle cramps. These results are shown in Table 6.

Table 6: Common Injuries suffered by Athletes

\begin{tabular}{lllll}
\hline Common injuries & Male $(\mathbf{n}=\mathbf{1 9 2})$ & & Female $(\mathbf{n}=90)$ \\
\hline & Frequency & Percentage & Frequency & Percentage \\
\hline & & & & \\
Hamstring & 83 & 43.2 & 17 & 18.8 \\
Tendon & 32 & 16.7 & 19 & 21.1 \\
Muscle cramps & 37 & 19.3 & 39 & 43.3 \\
Ankle & 40 & 20.8 & 15 & 16.7 \\
\hline
\end{tabular}

\subsubsection{Association between Common Injuries and Sex}

A chi square test and odds ratio was used to determine the association between sex and injuries suffered by athletes. From the chi square test, the findings indicated that more females were at risk of getting injured than males with a $\mathrm{P}$ value of 0.002 . Odds ratio indicated that females were 5.8 times more likely to suffer from injury than male athletes. These results are shown in Table 7. 
Table 7: Association between common injuries and sex

\begin{tabular}{|c|c|c|c|c|c|c|c|}
\hline Experiencing injuries & & & & & $\mathbf{O R}$ & $95 \% \mathrm{CI}$ & P value \\
\hline & Yes & & No & & & & \\
\hline & Frequency & $\%$ & Frequency & $\%$ & & & \\
\hline Male (n=190) & 160 & 83.3 & 32 & 16.7 & 5.8 & $1.726-$ & $0.002^{*}$ \\
\hline Female(n=92) & 87 & 96.7 & 3 & 3.3 & & 1.9487 & \\
\hline
\end{tabular}

\subsection{Dietary Intake of Energy, Iron and Calcium}

Significantly higher percentages of males met the RDA for the three nutrients than females. No female met the RDA for iron. The higher percentage that met the RDA for any of the three nutrients among males and females was about $35 \%$. The results are shown in the Table 8

Table 8: Dietary intake of Energy, Iron and Calcium

\begin{tabular}{|c|c|c|c|c|c|}
\hline Nutrient intake & RDA & Range of RDA & $\%$ RDAs & $\begin{array}{l}\text { \% meeting RDA or } \\
\text { More }\end{array}$ & $P$ value \\
\hline \multicolumn{6}{|l|}{ Energy (Kcal) } \\
\hline Male & $2200 \mathrm{kcal}$ & $1800-2900 \mathrm{kcal}$ & $81.8-131.8$ & 34.8 & \\
\hline Female & $2100 \mathrm{kcal}$ & $1000-2200 \mathrm{kcal}$ & $47.6-104.7$ & 6.3 & $0.002^{*}$ \\
\hline \multicolumn{6}{|l|}{ Iron } \\
\hline Male & $10 \mathrm{mg}$ & $7-11 \mathrm{mg}$ & $70-110.0$ & 21.7 & \\
\hline Female & $14 \mathrm{mg}$ & $6-9 \mathrm{mg}$ & $42.9-64.3$ & 0.0 & $0.048^{*}$ \\
\hline \multicolumn{6}{|l|}{ Calcium } \\
\hline Male & $1000 \mathrm{mg}$ & $700-1200 \mathrm{mg}$ & $70.0-120.0$ & 30.4 & \\
\hline Female & $1000 \mathrm{mg}$ & $500-900 \mathrm{mg}$ & $50.0-90.0$ & 12.3 & $0.042^{*}$ \\
\hline
\end{tabular}

\section{*Significant $<0.05$}

4.6.1 Association between Performance and Dietary Intake of Energy, Iron, Calcium and Nutritional Status Linear regression model was used to compute the association between performance and dietary intake of energy, iron, calcium and nutritional status. The findings indicated a positive association with a 2 tailed sigma of $<0.05$. These results are shown in Table 9.

Table 9: Association between performance and Dietary Intake of Energy, Iron, Calcium and Nutritional Status

\begin{tabular}{lllllll}
\hline & $\mathbf{B}$ & $\mathbf{R}$ & $\mathbf{r}^{2}$ & Sig & Lower CI(B) & Upper CI(B) \\
\hline Energy & 1.186 & 0.611 & 0.373 & $0.002^{*}$ & 0.507 & 1.865 \\
Iron & 0.486 & 0.515 & 0.266 & $0.001^{*}$ & 0.224 & 0.748 \\
Calcium & 0.002 & 0.300 & 0.090 & $0.004^{*}$ & 0.057 & 0.064 \\
Nutritional status & 0.588 & 0.561 & 0.315 & $0.000^{*}$ & 0.486 & 0.690 \\
\hline
\end{tabular}

\subsection{Categories of foods consumed by athletes}

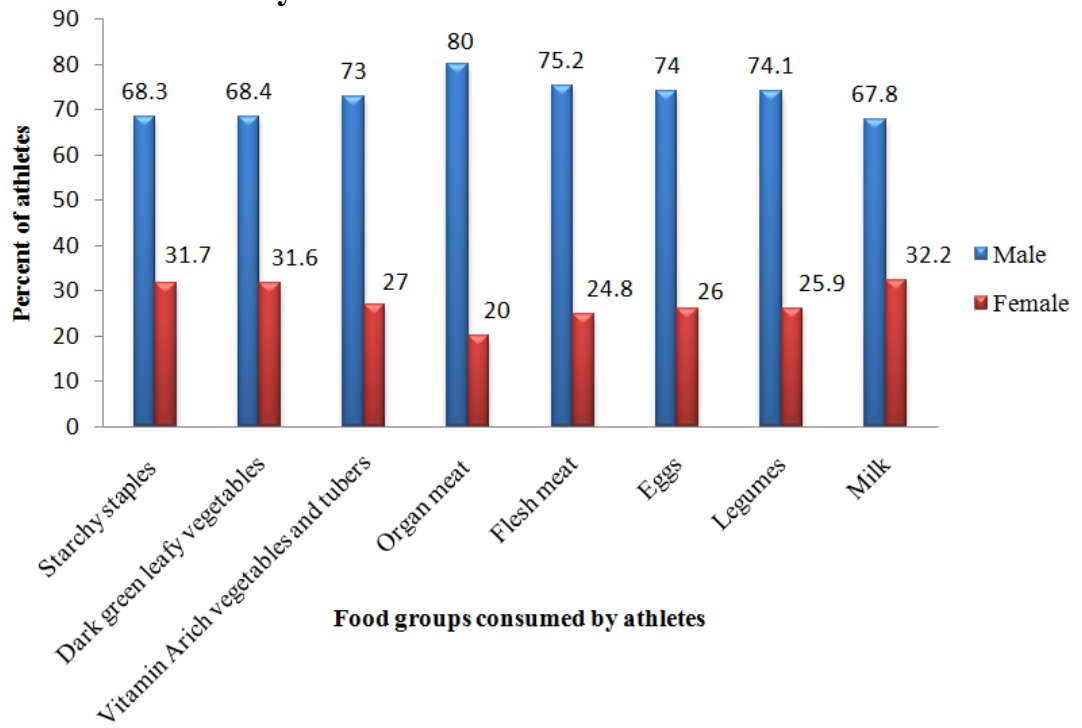

Figure 2: Categories of food groups consumed by athletes

Fig 2 shows the food groups as classified by FAO, (2010). From the study male athletes had the highest percentage in consumption of different food groups as compared to females with smaller percentage of consumption. Regression was used P 0.012 indicated that males had significantly higher consumption of the food groups than females. Starchy food had the highest consumption of $68.3 \%$ and $31.7 \%$ for males and females respectively. Consumption of milk and milk products which may have been consumed in tea, plain or fermented was also high. Fish, flesh meat, eggs and organ meat were the least among athletes. 


\subsection{Individual Dietary Diversity Score based on 24- hour recall}

Individual dietary diversity score (IDDS) were used to evaluate the dietary practices in terms of the numbers of food groups consumed out of the FAO recommended. Dietary diversity scores were calculated as the number of food groups consumed over a period of 24-hours. FAO cut-off points were used to classify Dietary Diversity Scores. The mean IDDS for the athletes was $4.34 \pm 0.45$. Significantly higher percentages of males had higher IDDS than females while significantly higher percentages of females had moderate IDDS than males. No athlete from the two groups had low IDDS. These results are shown in Table10.

Table 10: Individual Dietary Diversity Score

\begin{tabular}{|c|c|c|c|c|c|c|c|}
\hline \multicolumn{2}{|c|}{ Dietary diversity score } & \multicolumn{2}{|c|}{ Males $(n=192)$} & \multicolumn{2}{|c|}{ Females $(n=90)$} & \multirow[t]{2}{*}{$\chi^{2}$} & \multirow[t]{2}{*}{ P value } \\
\hline & & Frequency & $\%$ & Frequency & $\%$ & & \\
\hline $1-3$ & Low & 0 & 0.0 & 0 & 0.0 & & \\
\hline $4-7$ & Moderate & 119 & 62.0 & 74 & 82.2 & 11.625 & $0.001^{*}$ \\
\hline 8 and above & High & 73 & 38.0 & 16 & 17.8 & & \\
\hline
\end{tabular}

$\chi^{2}=$ Chi square "Significant $<0.05$

\subsection{Nutritional Status of Athletes}

The nutritional status of athletes was measured as BMI. Almost $50 \%$ of the male athletes had normal BMI as compared to $31.1 \%$ of the female athletes. More female athletes at $5.6 \%$ were severely underweight compared to male athletes at $1.6 \%$. None of the athletes was above normal BMI with the highest having BMI of $22 \mathrm{Kgs} / \mathrm{M}^{2}$. A chi square test was done with $\mathrm{P}$ value of 0.047 indicating that majority of the female athletes were underweight compared to male athletes. And odds ratio was done showing that female athletes were 0.701 times more likely to be underweight than male athletes. These results are shown in Table 11.

Table 11: Nutritional Status of Athletes

\begin{tabular}{|c|c|c|c|c|c|c|c|}
\hline Nutritional status & $\begin{array}{ll}\begin{array}{l}\text { Cut off } \\
\left(\mathrm{Kg} / \mathrm{M}^{2}\right)\end{array} & \text { BMI } \\
\end{array}$ & Male $(n=1$ & & $\operatorname{Female}(n=90)$ & & $\chi^{2}$ & $P$ value \\
\hline & & Frequency & $\%$ & Frequency & $\%$ & & \\
\hline \multicolumn{8}{|l|}{ Severely underweight } \\
\hline & $<16$ & 3 & 1.6 & 5 & 5.6 & & \\
\hline $\begin{array}{l}\text { Moderately } \\
\text { underweight } \\
\text { Mildly underweight }\end{array}$ & $16.0-16.99$ & 33 & 17.2 & 21 & 23.3 & 7.958 & $0.047^{*}$ \\
\hline & $17.0-18.49$ & 62 & 32.3 & 36 & 40.0 & & \\
\hline Normal & $>18.5-24$ & 94 & 48.9 & 28 & 31.1 & & \\
\hline
\end{tabular}

*significant $<\mathbf{0 . 0 5}$

\subsubsection{Association between Dietary intake of Calcium, Energy, Iron with injury}

Logistic regression was used to show relationship between dietary intake of calcium, energy and iron with injury. Injury was statistically significant $(\mathrm{P}<0.05)$ in associated with dietary intake of calcium and iron but not energy. This indicated that insufficient intake of calcium and iron would make athletes more likely to suffer injuries during the event. The Exp (B) indicated that athlete's who had inadequate dietary intake of calcium and iron were about two times more likely to suffer injuries than those who had sufficient intakes. Inadequate dietary intake of energy was not significantly associated with injury. These results are shown in Table 12 .

Table 12: Association between Dietary Intake of Calcium, Energy, Iron and Injury

\begin{tabular}{lllll}
\hline Energy and nutrient intake & $\mathbf{B}$ & Wald & Sig & Exp (B) \\
\hline Calcium & 0.012 & 5.385 & $0.020^{*}$ & 1.989 \\
Energy & 0.003 & 3.521 & 0.061 & 1.003 \\
Iron & 0.682 & 5.495 & $0.019^{*}$ & 1.979 \\
\hline
\end{tabular}

*significant at $\mathrm{p}<0.05 \quad$ B-regression coefficient

Wald- Wald statistics $\quad$ Sig - significance level

Exp (B) - odds ratio

\subsubsection{Association between Dietary Intake of Calcium, Iron and Energy with Fatigue}

Association between dietary intake of energy and iron was statistically significant with $\mathrm{P}<0.05$ while association between fatigue and dietary intake of calcium was not statistically significant. The Exp (B) indicated that athletes with inadequate dietary intake of energy were 1.549 times more likely to experience fatigue during competition than those with adequate intake. Inadequate dietary intake of calcium does not predispose athletes to fatigue. These results are shown in Table 13. 
Table 13: Association between Dietary Intake of Calcium, Iron and Energy with Fatigue

\begin{tabular}{lllll}
\hline Energy and nutrient intake & B & Wald & Sig & Exp (B) \\
\hline Calcium & 0.003 & 1.542 & 0.214 & 1.005 \\
Iron & 0.688 & 3.502 & $0.041^{*}$ & 1.003 \\
Energy & 0.002 & 1.243 & $0.048^{*}$ & 1.549 \\
\hline
\end{tabular}

4.9.3 Association between Dietary intake of Iron, Calcium and Energy and loss of breath Dietary intake of iron had a significant relationship with loss of breath (P 0.025) and the Exp (B) indicates that athletes who had inadequate intake of iron were two times more likely to experience loss of breath during intense exercise. These results are shown in Table 14.

Table 14: Association between Dietary intake of Iron, Calcium and Energy with loss of breath

\begin{tabular}{lllll}
\hline Energy and nutrient intake & $\mathbf{B}$ & Wald & Sig & Exp (B) \\
\hline Iron & 0.686 & 5.000 & $0.025^{*}$ & 1.985 \\
Calcium & 0.002 & 0.705 & 0.401 & 1.002 \\
Energy & 0.000 & 0.109 & 0.741 & 1.000 \\
\hline nificant at p<0.05 & B-regression coefficient & & \\
ld- Wald statistics & Sig - significance level
\end{tabular}

Wald- Wald statistic

Exp (B) - odds ratio

\section{Discussion}

Kenyan athletes are renowned over the World for their endurance running in middle and long distance races. Successful athletes in Kenya have been found to span ages from 18 years up to about 40 years, for example a 35 year old Mary Keitany won the London marathon 2017. In this study however, the age span was between 18-30 years and it was purposively selected to be so. More of male athletes were between ages $25-30$ years while for the females most of them were between ages $18-24$ years. This was similar to a recent study of the Ethiopian elite runners who were found to have majority between ages of $24-32$ years Scott, $(2008){ }^{[8]}$. This is probably because after 30 years of age most female retire from sports and settle to other responsibilities including motherhood which reduce their time for active practice. Most of the athletes were single this could be because married athletes' especially female athletes have roles such as pregnancy, lactation and childbearing and caring for the children, which reduce their commitment to athletics. A small percentage of athletes never attended school while most of them had secondary education with a few of them with tertiary education. These findings were similar to those by Kibata (2011) ${ }^{[9]}$ for elite athletes who were on practice to attend an international competition. Most of athletes achieved secondary education and turned to sports because of low employment rates in Kenya. Successful athletics is a personal initiative which does not require academic qualification and earns income, most often more than from employment. Majority of them were from Kalenjin community especially Nandi and Keiyo sub-tribe. The Kalenjin have continued to dominate internationally long distance and middle distance racing, for reasons that are still not well explained. This has attributed to thin the body physical appearance, less mass for height, longer legs, slender limbs, shorter torsos and thin ankle describes a "bird like" Pitsiladis et al., (2012) ${ }^{[10]}$

Most athletes were farmers and self employed in small businesses. Few were employed in the civil service of Kenya Army, Kenya police force and prisons. The economic class of most of them was second class with a small percentage in higher class level. This is probably due to low income from business and temporary employment. Employees of the disciplined forces routinely run long distance each day in order to keep fit. Some of them will take advantage of this exercise and extend it as a practice for athletics.

The athletes in the training camp were training twice per day in the morning and in the evening and the types of exercises included tempo, track session, fartlek, hillrun, situps, stretching among others. According to the trainers, these exercise help to enhance and maintain the performance. This is supported by Billat et al., (2003) ${ }^{[11]}$ that the intensive training methods with consistent running at race pace contribute to the success of athletes' performance. It was also reported by Onywera et al (2006) ${ }^{[12]}$, that early introduction of children at early ages to running and extensive walking to and from school (about 5-20 kilometre). According to history of Kalenjin, children usually stand as herders which give them practice in running as they chase the sheep across the countryside in high altitude and hilly regions of the Rift Valley. Another possible explanation to their outstanding performance is chronic exposure to high altitude whereby, Iten training camp is a high altitude about 2400 meters above sea level. These could help runners develop lungs capable of functioning in thinner air and can lead to superior levels of haemoglobin and hematocrit which in turn leads to an increased ability to transport oxygen to the working muscles Beis et al., $(2011)^{[13]}$. Another possible reason for the outstanding performance is the motivation created by the opportunity to achieve economic success. Since Kenya is among the developing countries and with high unemployment rate among the youth, running is perceived as employment opportunity which can considerably advance an athlete's position in the society (Onywera et al., 
2006) ${ }^{[12]}$. Most athletes participated in long distance running; marathon $(42 \mathrm{~km})$ and half marathon $(21 \mathrm{~km})$. In 10,000meters, half marathon and full marathon there were always more males than females. Kenyan male athletes have dominated long distance running for decades. It is only in this study recently that females have emerged as participants in marathon and half marathon. Most of the athletes achieved at least good performance, with about $25 \%$ of them achieving excellent performance when rated against the performance of 2016 RIO Olympics.

The injuries that was common and frequent to athletes included tendon injury, hamstrings, muscle cramps and ankle injury. Athletes have a misconception that injuries are normal and cannot be avoided due to training on tarmac roads and worn out shoes among others. But evidence exist that most occur due to nutrient deficiencies like calcium, energy and iron. Significantly more female athletes experienced injuries than male athletes. This is probably due to inadequate dietary intake of iron, calcium and energy; this is due to fear of adding weight. For females also fatigue, female athlete triad may have hindered them from achieving good performance. During strenuous activities like running and exercising vigorously, there is increased need for macro and micro-nutrients and if these demands are not met then the risk of injuries such as stress fractures increases Hedrick et al., (2013) ${ }^{[14]}$. Apart from poor diet, there are other contributing factors to injuries including environmental, anatomical, hormonal, biochemical and neuromuscular factors.

Individual 24-hour recall was used to assess the dietary intake of athletes and thereafter Nutri-survey 20.0 software and food composition table was used to compute dietary intake of energy, iron and calcium. The recommended dietary intake of energy for male athlete is $2200 \mathrm{Kcals}$ and that of females is $2100 \mathrm{Kcals}$ per day. Only $6.3 \%$ of female athletes and $34.8 \%$ of males met the RDA for energy. Carbohydrate intakes should be approximately $70 \%$ of the total daily calories and fats providing about $25-30 \%$ of total daily calories so as to meet the recommended dietary intake. It was not possible in the current study to partition the intake of energy into the two components.

Calcium is important for growth, maintenance and repair of bone tissue, maintenance of blood calcium levels, regulation of muscle contraction, nerve conduction, and normal blood clotting. Inadequate dietary calcium and vitamin D increase the risk of low bone mineral density, stress fractures and a contribution to female athlete triad. Female athletes are at greater risk for low bone mineral density if energy intakes are low, calcium-rich foods are inadequately consumed and menstrual dysfunction is present. Only $12.3 \%$ of females and $30.4 \%$ of males met the RDA for calcium. Most male athletes consumed foods rich in calcium such as milk and milk products and legumes, nuts and cereals compared to females with low consumption of foods hence making the females be more susceptible to injuries than males.

Iron is required for the formation of oxygen-carrying proteins, hemoglobin and myoglobin, and for enzymes involved in energy production. Oxygen-carrying capacity is essential for endurance exercise as well as normal function of the nervous and immune systems. Iron depletion is one of the most prevalent nutrient deficiencies observed among athletes, especially females. Iron deficiency, with or without anaemia, can impair muscle function and limit work capacity. Iron requirements for endurance athletes, especially distance runners are increased by approximately $70 \%$. RDA, $>14 \mathrm{mg}$ and $>10 \mathrm{mg}$ for women and men respectively. The high incidence of iron depletion among athletes is usually attributed to inadequate energy intake. Other factors that can impair iron status are training at high altitudes, increased iron losses in sweat, feces, urine, and menstrual blood for females, intravascular hemolysis, foot-strike hemolysis and injury. Findings from the study showed that none of the female athlete met the recommended dietary intake of iron, while $21.7 \%$ of male athletes met the RDA. This is evident with a smaller percentage of female athletes consuming iron rich foods such as dark green leafy vegetables, organ meat, flesh meat and eggs, as a result predisposing them to loss of breath, fatigue and exhaustion during competition thus obtaining poor performance. Similar results were published by Rodrigeuz et al (2007) ${ }^{[15]}$.

Based on various food groups, consumption of starchy staples was highest at $99.6 \%$ closely followed by consumption of dairy products at $87.9 \%$ and consumption of dark green leafy vegetables at $75.2 \%$. The least consumed food group was organ meat at $19.7 \%$ and fish at $12.1 \%$. The staple food in the community is maize as ugali (a paste from hot water and maize meal) and is mainly consumed with vegetables and milk (fresh milk and "mursik" traditional fermented milk). The findings of this study also agree with a study by Onywera et al. (2006) ${ }^{[12]}$ that the common diet was mainly ugali. Starchy cereal staples were the most consumed food group, due to the easy availability. Moreover considering that most of the athletes were farmers and the most grown crop in Kenya is maize. Dark green vegetables such as kales were also consumed in plenty due to their availability. Milk and milk products were highly consumed too; this could be to the probable routine that individuals take either tea coffee or cocoa in combination with milk or plain milk with a meal. Cereals are the main source of carbohydrates energy while leafy vegetables are rich sources of iron and milk and milk products are rich sources of calcium. The foods groups that were least consumed were organ meats, fish. Low intake of fish and organ meat could be due their prices at the market are high and also inadequate availability in the region. Most of the athletes were on moderate dietary diversity score with the mean dietary diversity score of 4 
\pm 1 . According to FAO (2010), a DDS of 4 shows moderate intake of micronutrients. Since Individual dietary diversity scores aim to reflect nutrient adequacy, this would therefore imply that most athletes were taking slightly adequate nutrients, which does not agree with the findings of the dietary intake of energy, iron and calcium which showed that maximum 30\% of athletes met the RDA for the nutrients. Such contradictions would arise in a situation where the athletes are not consuming the nutrient rich foods in sufficient amounts.

Nutritional status of athletes was calculated as BMI Body Mass Index). From the study, most (57.2\%) of the athletes were underweight $(<18.5)$ with more females being underweight than males. This may be due to disordered eating resulting to female athlete triad which comprises of energy deficiency, menstruation dysfunction and low bone mass. This is due to desire for body image and high thrives for thinness. Also, though diet is perceived as nutritionally adequate, general Kenyan diet consist of simple foods with high starch comprising of maize and beans. Therefore, nutrition education and other contributing factors thus are not seen important since the performance has been outstanding for decades Onywera et al., (2006) ${ }^{[12]}$

These findings are supported by study of Kibata $(2011)^{[9]}$ which showed that female athletes had lower nutritional status than males. The female endurance athletes reported experiencing amenorrhea with 79\% experiencing changes in their menstruation cycle including skipping and missing for more than three month due to heavy training, thus reflecting poor dietary intake and as a result poor nutritional status.

Linear regression model was used to compute relationship between dietary intake of energy, iron and calcium and the performance of the athletes. There was a positive association between dietary intake of the three nutrients and the performance of athletes. The positive association between performance and energy intake is that when there is increased intake of dietary energy, the performance is increased and is similar to iron, and calcium hence an outstanding performance is achieved. This is simply because good dietary intake of energy, iron and calcium will eliminate injuries, loss of breath, fatigue and other hindrances to performance.

Logistic regression in this study was used to show the association between injury and dietary intake of calcium, fatigue and dietary intake of calcium and iron and lose of breath and dietary intake of iron. The result of regression is usually an equation model which summarizes the relationship between the dependent and independent variables. Athletes with adequate intake of dietary calcium and energy foods were less likely to suffer injuries as compared to those consuming less calcium rich foods. This is probably because calcium plays an important role in maintenance and repair of bone tissue, maintenance of blood calcium levels, regulation of muscle movement and nerve conduction. Calcium deficiency acts as a resistance in successful training and competition because when calcium store is not adequate to be drawn upon by skeletal formation process, the athletes' bones will not be strong and supportive for endurance performance due to poor transmission of body's response signals.

Iron is important in transporting oxygen from ambient air into the working muscles. Athletes who had low dietary iron intake experienced shortness of breath and fatigue which as a result hindered them from achieving optimum performance. This is because inadequate iron stores causes sensation of shortness of breath during exercise ultimately due to decreased availability of oxygen to the working muscles. When oxygen is not transported effectively to the working muscle, it causes a build up in lactic acid in the muscle which as a result causes fatigue and soreness in muscles. More females experienced shortness of breath and fatigue as compared to males because the study established females consumed less iron rich food and low caloric dense foods and also loss blood from menstruation every month. The low consumption of energy foods resulting from fear of adding weight and attaining a smaller body mass for athletics Glaister, $(2005)^{[16]}$

\section{Conclusions And Recommendations}

The study concludes that most of the athletes were between ages of 25-30 years with more females between $18-25$ years. Majority of the athletes had a secondary education with a small portion having tertiary education. Majority of the athletes were from Kalenjin community due to their renowned outstanding performance for decades. Most of the athletes were farmers or self employed and the income from sports was to sustain their livelihood and boost their socio-economic class. Majority of them were in the middle income class. It was established that majority of athletes achieved good performance with more males running marathon and half marathon races and more females running middle distance races. Athletes experienced injuries, loss of breath and fatigue which were the major hindrance to performance due to inadequate dietary intake of energy, iron and calcium. It was established that athletes had inadequate dietary intake of energy, iron and calcium with more of the female athletes not meeting the recommended dietary intake. The overall nutritional status of athletes as measured as BMI was poor. Therefore, nutrition education should be incorporated into training activities of athletes and Athletics Kenya with other stakeholders should establish a structured nutrition training program and guidelines to be followed by all training camp coaches and athletes so as to promote nutrition education and achieve a desired eating practice among athletes. Education strategies for sports professionals should focus on the roles of selected nutrients in exercise so as to encourage athletes to practice sound nutrition practices rather than doping to maximize their performance 


\section{Reference}

[1] Fudge, B. W., Westerterp K. R., Kiplamai F. K., Onywera V.O., Boit M. K., Kayser B., and Pitsiladis Y. P., Elite Kenyan Long Distance Runners are in Negative Energy Balance. British Journal of Nutrition 95, 2006, 59 - 66.

[2] Tipton KD. Nutrition for acute exercise - induced injuries. Annals of nutrition metabolism, 2010, 43-45

[3] IAAF. Nutrition for athletics: The 2007 Consensus Statement of the International Association for Athletics Federation. Journal of Sports Science 30,2007

[4] Burke, L. M., Meeting energy needs. Canadian Journal of Applied Sports Science 26, 2001, 202 - 219.

[5] Fischer, A.A; Laing, J.E; and Townserd, J.M. Handbook for family planning operative Research Design $2^{\text {nd }}$ edition, population council, (New York 45, 1991)

[6] KNBS. Kenya Population and Housing Census, Volume I A; Population by Administrative Units, Kenya National Bureau of Statistics, Nairobi, Kenya. Volume 1 A, 2009

[7] Sehmi, J. K. (1993). National Food Composition Tables and Planning of Satisfactory Diets in Kenya. Government Printer. Nairobi.

[8] Scott RA, Georgiades E, Wilson RH, Goodwin WH, Wolde B, Pitsiladis YP. Demographic characteristics of elite Ethiopian endurance runners. Med Sci Sports Exerc.;35,2008, 1727-1732

[9] Kibata Murugi Freda. Nutrition Knowledge, Dietary Intake and Nutritional status of Elite Kenyan Athletes masters diss., University of Nairobi, 2011

[10] Pitsiladis Y.P., Onywera V.P., Geoglades E., O'Connell W., Boit M.K., The dominanace of Kenyans in distance running. Equine Compor Exerc. Physiol 1(4),2004, 285 - 291

[11] Billat V, Lepretre PM, Heugas AM, Laurence MH, Salim D, Koralsztein J.P.A. Training and bioenergetic character-istics in elite male and female Kenyan runners. Med Sci Sports Exerc.; 35, 2003,297-304.

[12] Onywera VO, Scott RA, Boit MK, Pitsiladis YP. Demographic characteristics of elite Kenyan endurance runners. J Sports Sci.24, 2006, 415-422.

[13] Beis L.Y., Willikomm L.,Ross R, Bekele Z, Wolde B, Fudge B . Pitsiladis YP.Food and Micronutrient intake of elite Ethiopian distance runners. J Int Soc Sports Nutr. 2011

[14] Practical Applications in sports Nutrition $2^{\text {nd }}$ ed. Energy systems in the body.( Hedrick H.F, Lisa A. Burgon, A. Mikesky E, 2013)

[15] Rodriquez NR, DiMarco NM, Langley S(2012) Position of the American Dietetic Association, Dietitians of Canada, and the American College of Sports Medicine: Nutrition and athletic performance. J Am Diet Assoc 2012, 509-527

[16] Glaister, M. Multiple Sprint Work. Physiological responses, Mechanisms of fatigue and the influence of aerobic fitness. Sports Medicine; 2005, 757-777

Caroline Tanui. "Association between Performance and Injury with Dietary Intake and Nutritional Status among Athletes: Case of Iten Training Camp in the Rift Valley of Kenya." IOSR Journal of Sports and Physical Education (IOSR-JSPE) 4.3 (2017): 62-71. 